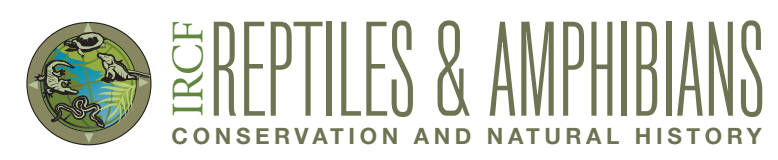

\title{
An Instance of a House Gecko (Hemidactylus frenatus Schlegel, 1836) Utilizing an Electrical Timer for Thermoregulation
}

\author{
Gerrut Norval ${ }^{1}$ and Jean-Jay Mao ${ }^{2}$ \\ 'Applied Behavioural Ecology and Ecosystem Research Unit, Department of Environmental Sciences, University of South Africa, \\ Private Bag X6, Florida, 1710, Republic of South Africa (gnorval@gmail.com) \\ ${ }^{2}$ Department of Forestry and Natural Resources, National Ilan University, No. 1, Sec. 1, Shen-Lung Rd., Yilan, 260, Taiwan, R.O.C.
}

Photographs by the senior author.

$\mathrm{T}$

The Asian House Gecko (Hemidactylus frenatus Schlegel, 1836; Fig. 1) is primarily an Oriental species (Case et al. 1994), but has spread (often human-mediated) pantropically (Case et al. 1994; Rödder et al. 2008; Hoskin 2011).
In Taiwan, this gecko species occurs at altitudes below 1,000 $\mathrm{m}$ islandwide and on the outlaying islets, but tends to be less frequently encountered in northern parts of the main island (Shang and Lin 2001; Lue et al. 2002). Herein we describe

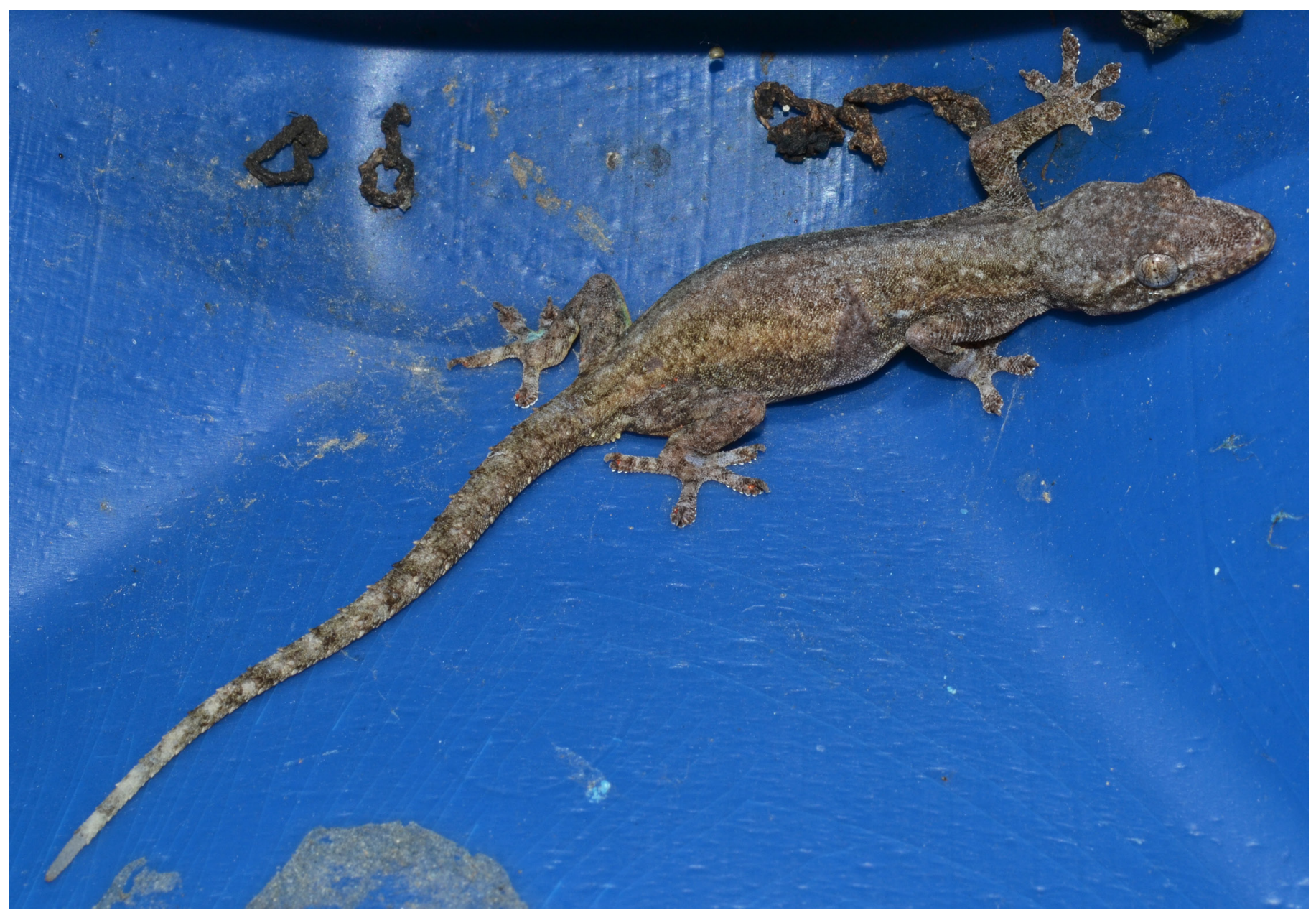

Fig. 1. The Asian House Gecko (Hemidactylus frenatus) is abundant in low elevation urban areas in most parts of Taiwan. 


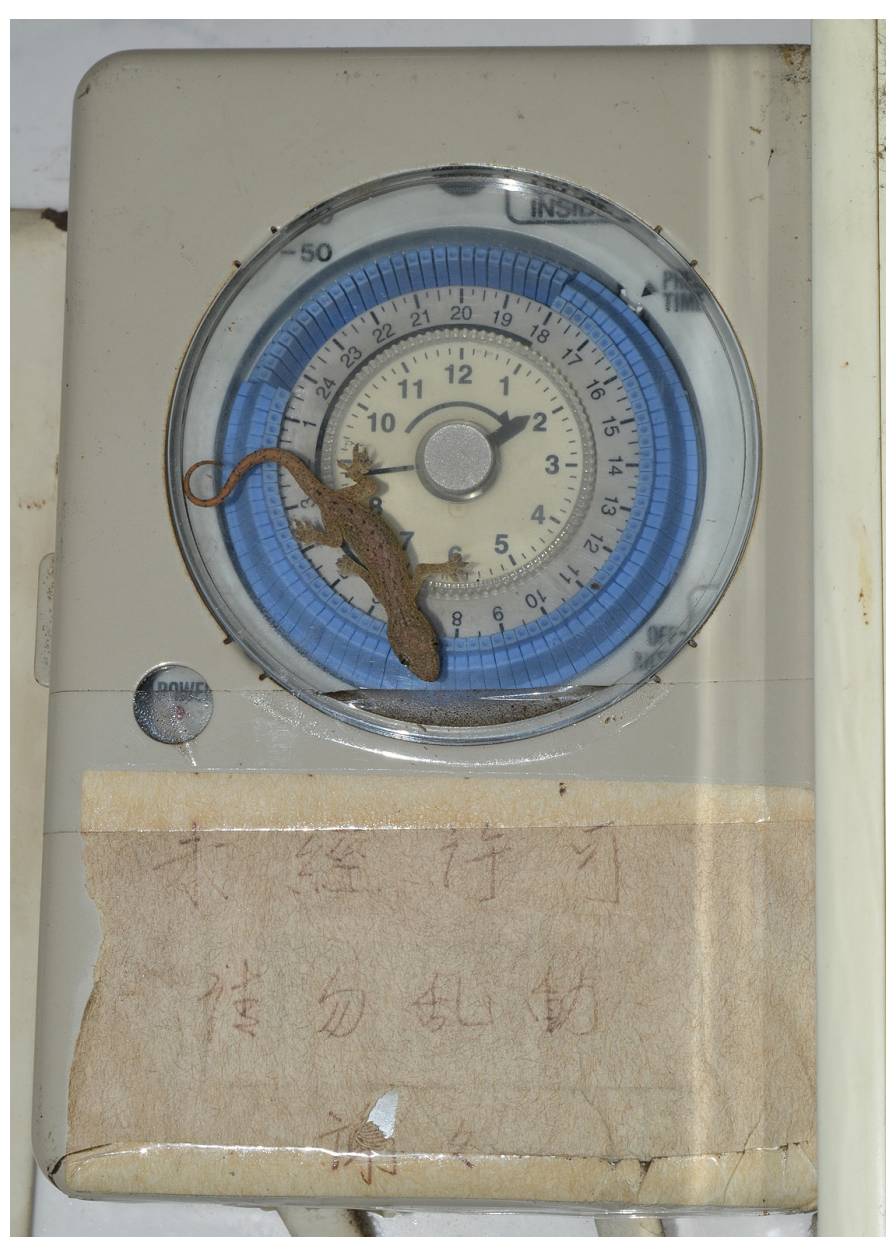

Fig. 2. The juvenile Asian House Gecko (Hemidactylus frenatus) described herein on the transparent plastic display window of an electrical timer.

observations of a $H$. frenatus that was observed utilizing an electrical timer as a heat source for thermoregulation.

On 21 November 2014 at ca. $1800 \mathrm{~h}$, the senior author noticed a juvenile $H$. frenatus (SVL ca. $25 \mathrm{~mm}$ ) on the exterior of a transparent plastic window that covers the dial of an electric timer (Fig. 2). The timer was attached ca. $1.7 \mathrm{~m}$ above the ground on a tiled wall of an entrance corridor of an apartment building in Chiayi City, southwestern Taiwan (23⒉'24"N, $\left.120^{\circ} 25^{\prime} 20^{\prime \prime E}\right)$. The gecko fled when it was approached for closer observation. At ca. $1930 \mathrm{~h}$ and $2300 \mathrm{~h}$, the gecko was observed at the same location and each time it fled when attempts were made to approach it. On 22 November 2014 at ca. $1900 \mathrm{~h}$ and $2300 \mathrm{~h}$, the gecko was again observed at the same locality. During the second observation a WISEWIND combined humidity and temperature indicator was used to measure the temperature of the position on the plastic where the gecko was observed, as well as the temperature of the tiles next to the timer. The spot on the plastic had a temperature of $28.1^{\circ} \mathrm{C}$, whereas that of the tiles was $25.1^{\circ} \mathrm{C}$. On the days following these observations the temperatures became too cool for gecko activity. Yet, this individual was seen on a daily basis (sometimes even during the day) at the same position on the timer. We thus believe that the gecko was using the timer for thermoregulation.

Even though $H$. frenatus can occasionally be observed basking in the sun (heliothermy) during the day (Fig. 3), this species is primarily nocturnal, and absorbing heat by contact with warm surfaces (thigmothermy) can be expected to be its main method of thermoregulation.

Hemidactylus frenatus is known to be attracted to indoor and outdoor lights, where it feeds on insects that also are attracted to the lights (Newberry and Jones 2007). However, since such lights usually also emit heat, these geckos very likely also utilize them for thermoregulation. In another instance we reported on geckos being attracted to the heat generated by electrical components of air conditioning units (Chang et al.

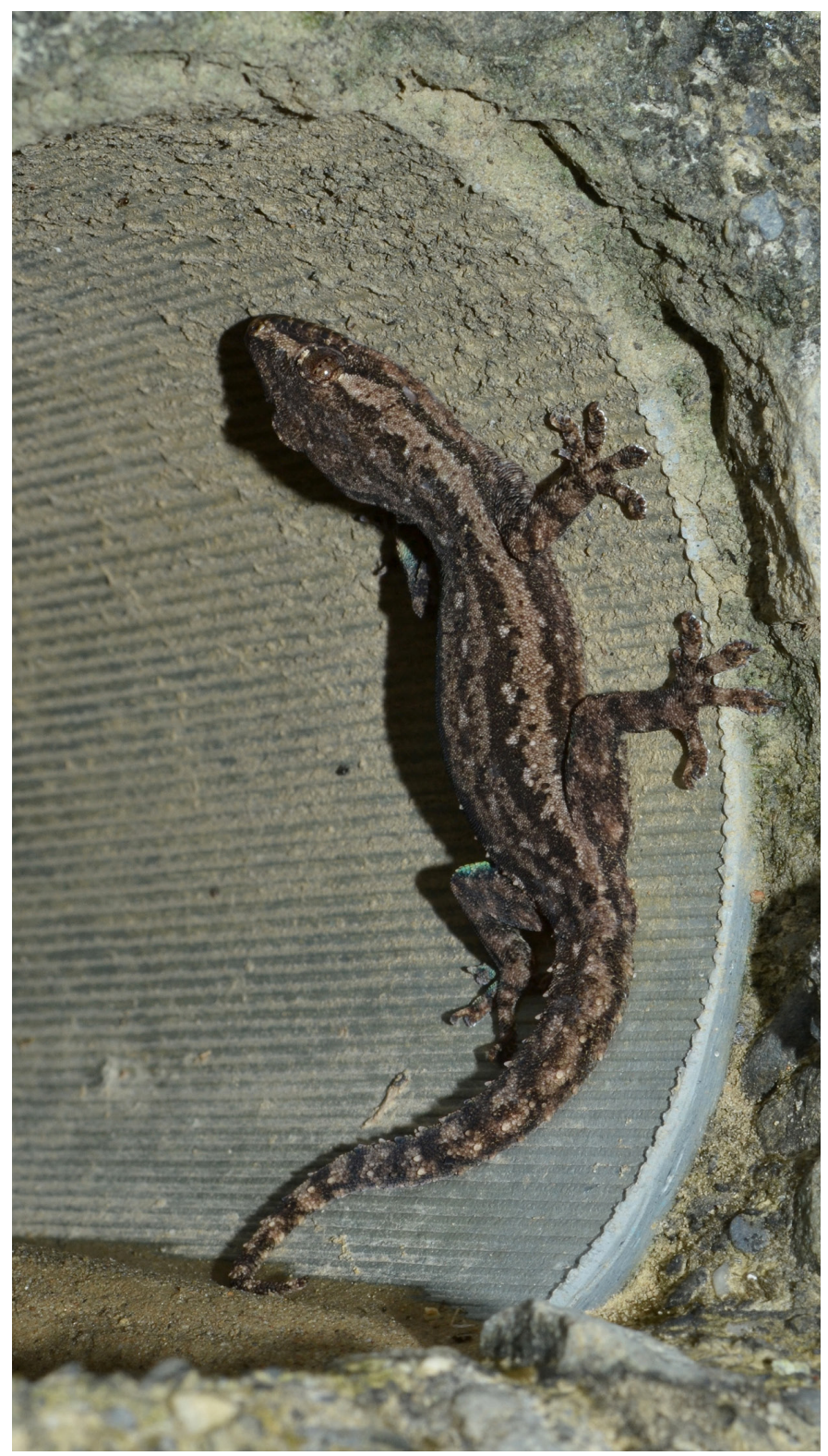

Fig. 3. An Asian House Gecko (Hemidactylus frenatus) basking in the sun at the outlet of a drainage pipe. 
2013). The observations described herein demonstrate that even relatively cool electrical devices can be utilized by these human-commensal lizards for thermoregulation.

\section{Literature Cited}

Case, T. J., T. Bolger, and K. Petren. 1994. Invasions and competitive displacement among house geckos in the tropical Pacific. Ecology 75:464-77.

Chang, C.W., J.J. Mao, and G. Norval. 2013. Damage to air conditioning units caused by geckos. Reptiles \& Amphibians 20:143-145.

Hoskin, C.J. 2011. The invasion and potential impact of the Asian House Gecko (Hemidactylus frenatus) in Australia. Austral Ecology 36:240-251.
Lue, K.Y., M.C. Tu, and G.S. Shang. 2002. The Transition Kingdom - Guidebook of Amphibians and Reptiles of Taiwan. SWAN, Taipei, Taiwan (in Chinese).

Newberry, B. and D.N. Jones. 2007. Presence of Asian House Gecko Hemidactylus frenatus across an urban gradient in Brisbane: Influence of habitat and potential for impact on native gecko species, pp. 59-65. In: D. Lunney, P. Eby, P. Hutchings, and S. Burgin (eds.), Pest or Guest: The Zoology of Overabundance. Royal Zoological Society of New South Wales, Sydney, Australia.

Rödder, D., M. Solé, and W. Böhme. 2008. Predicting the potential distributions of two alien invasive housegeckos (Gekkonidae: Hemidactylus frenatus, Hemidactylus mabouia). North-Western Journal of Zoology 4:236-246.

Shang, G.S. and S.L. Lin. 2001. Natural Portraits of the Lizards of Taiwan. Big Trees Publishers, Taipei, Taiwan (in Chinese). 